\title{
The Link Between Organizational Agility And VUCA - An Agile Assessment Model
}

https://doi.org/10.21272/sec.5(1).35-43.2021

Henning Bundtzen, ORCID ID: https://orcid.org/0000-0002-0098-8886

PhD Candidate, Szent István University in Budapest, Hungary; MBA; Organizational Developer, Germany

Gerriet Hinrichs, ORCID ID: https://orcid.org/0000-0002-4490-3856

PhD Candidate, Szent István University in Budapest, Hungary

\begin{abstract}
This paper summarizes the elements of agility listed in contemporary scientific literature and aligns them to the four different forces described by the acronym VUCA. There is a general consensus that organizational resilience and agility are crucial elements to gain sustainable competitive advantage especially since the arresting economic changes during the pandemic year 2020. There is little agreement though how precisely organizational agility responds to volatility, uncertainty, complexity, and ambiguity (VUCA). By systemization of frameworks and models from the literary sources the aim is to create a combined model. Consequently, the purpose of this paper is to develop a model that can practically be employed to evaluate the agile status quo of an organization. It should support practitioners to distinguish between the different requirements each part of the VUCA acronym requires. The design of this study is a conceptual paper which proposes a new corporate agility model with direct linkages to the requirements of VUCA forces. It derives from, and builds on, existing scientific literature while integrating a comprehensive set of existing agile frameworks. The result of this research is a model which defines distinct enablers, sensing capabilities, agile practices, and responses as answers to VUCA forces. It highlights that certain elements reinforce and link to each other to transform an entire organization agile. Surprisingly, leadership and strategy are not incorporated as elements but rather seen as conditions that subordinate the iterative learning approach of this model. Originality is given as the created model provides a set of elements leaders can implement or use to assess organizational agility. Furthermore, it supports how to deal with strategy and leadership in the transitional process. Relevance is given as during the worlds COVID-19 crises the economic and governments changes in terms of volatility and uncertainty were especially challenging for organizations.
\end{abstract}

Keywords: agile organization, VUCA, agile strategy, leadership in agility, organizational development, COVID-19. JEL Classification: M21, M14, M15, L21, F20.

Cite as: Bundtzen, H., Hinrichs, G. (2021). The Link Between Organizational Agility And VUCA - An Agile Assessment Model. SocioEconomic Challenges, 5(1), 35-43. https://doi.org/10.21272/sec.5(1).35-43.2021.

Received: 14.02 .2021

Accepted: 27.03.2021

Published: 30.03 .2021

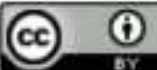

Copyright: (C) 2021 by the authors. Licensee Sumy State University, Ukraine. This article is an open access article distributed under the terms and conditions of the Creative Commons Attribution (CC BY) license (https:// creativecommons.org/licenses/by/4.0/).

\section{Introduction}

The pandemic crisis in 2020 showed arrestingly how fast and in which magnitude economic conditions can change for an organization. Commonly this scenario is described by the term VUCA which stands for volatility, uncertainty, complexity, and ambiguity. Seldom has the economic environment been as turbulent and changes happen so fast as in 2020. One answer to VUCA are agile working practices and an organizational structure that is able to react flexible and fast to economic alterations evoked by changing consumer preferences, technological leaps or even lock downs of the social life (Ganguly et al., 2009). The aim of this qualitative literature review is 
to develop a comprehensive and in practice applicable model on how organizations respond to these economic scenarios.

There are numerous models and frameworks about organizational agility in scientific literature. Practitioners who want to assess how prepared their own organization is to cope with the VUCA challenges have subsequently difficulties to find a structure that explains the linkages as well as elements they could rate (Ganguly et al., 2009) and at which part of the VUCA terminology each aims. Possibly a part of the by the acronym described forces is pronounced in comparison to others. Consequently, the aim of this research is not only to create a holistic model on corporate agility that links to volatility, uncertainty, complexity, and ambiguity. In addition, it needs to be condensed to ensure practical applicability.

In a broad context a lot of research focuses on IT capabilities to achieve organizational agility (Ravichandran, 2018; Felipe et al., 2016; Cepeda and Arias-Pérez, 2019; Shams et al., 2020) while other research lists a comprehensive set of enablers and capabilities that lead to organizational agility (Eshlaghy et al., 2010; Sherehiy et al., 2007). Agile practices are mainly derived from IT project management methods like Scrum or the utilization of Kanban boards. Especially elements of Scrum are transferred to a structural level of entire organizations to make the advantages not only in projects applicable.

Apart from the increasing dynamic of economic changes which make organizational agility a necessity rather than a nice to have scientific research advocates a positive impact on a company's performance (Ravichandran, 2018). It has to be highlighted though that company size, age and industry have a mediating role when transforming an enterprise from bureaucratic hierarchy to agile teamwork (Ravichandran, 2018). A company that is born agile or operative in a highly volatile and technologically fast developing market will surely find it easier to make progress in becoming agile as there is an external force for it. But to be prepared for big economic changes all company leaders should engage into agile concepts as COVID-19 has impressively enlightened. This included any industry, be it considerably stable and growing, like aviation or hospitality still experienced heavily the by VUCA described changes. The aim of this research is not only to create a new model that explains the interlinkages between agile methods and VUCA. In addition, it should be commonly understandable outside the scientific world and ideally be available to be implemented in advisory for the development of corporate culture with a focus on unstable economic situations and agility. Thus, for visualization purposes the model should be ajar to the Denison model of organizational culture to construe a comprehensible and practical established model. Denison's organizational culture model is well recognized and used for analysing and advising on corporate culture, performance, and efficiency (Denison, 1984).

\section{Literature Review}

A review of current scientific literature was conducted to evaluate the theoretical and practical answers to the challenges of the VUCA world. Research was sighted to get an overview of frameworks, models, and theories that describe how organizations can address dynamic economic challenges. The following table lists the research that was integrated into the conceptual model created in this paper. In addition, a short paragraph highlights which and how the concepts were integrated into the final model on corporate agility of this paper.

Table 1. Research articles integrated into the corporate agility model

\begin{tabular}{|l|l|l|}
\hline \multicolumn{1}{|c|}{ Author } & \multicolumn{1}{|c|}{ Title } & \multicolumn{1}{|c|}{ Concepts integrated } \\
\hline $\begin{array}{l}\text { Appelbaum, Steven H.; Calla, } \\
\text { Rafael; Desautels, Dany; } \\
\text { Hasan, Lisa }\end{array}$ & $\begin{array}{l}\text { The challenges of organizational } \\
\text { agility }\end{array}$ & $\begin{array}{l}\text { Components to respond to the challenges of organizational agility, e.g. } \\
\text { strategic commitment, environmental scanning and adaptable network } \\
\text { structures. }\end{array}$ \\
\hline $\begin{array}{l}\text { Baran, Benjamin E; Woznyj, } \\
\text { Haley M. }\end{array}$ & $\begin{array}{l}\text { Managing VUCA: The human } \\
\text { dynamics of agility }\end{array}$ & $\begin{array}{l}\text { Connection between obstacles to manage VUCA and the recommended } \\
\text { practices for overcoming these challenges. Precondition of leaders' sense } \\
\text { needs and opportunities for change. }\end{array}$ \\
\hline $\begin{array}{l}\text { Baškarada, Saša; Koronios, } \\
\text { Andy }\end{array}$ & $\begin{array}{l}\text { The 5S organizational agility } \\
\text { framework: a dynamic capabilities } \\
\text { perspective }\end{array}$ & $\begin{array}{l}\text { Agile framework consisting of sensing, searching, seizing, shifting, and } \\
\text { shaping as an agile response to external changes. }\end{array}$ \\
\hline $\begin{array}{l}\text { Bennett, Nathan; Lemoine, G. } \\
\text { James }\end{array}$ & $\begin{array}{l}\text { What a difference a word makes: } \\
\text { Understanding threats to } \\
\text { performance in a VUCA world }\end{array}$ & $\begin{array}{l}\text { Distinctions within the VUCA framework on how these challenges can be } \\
\text { effectively addressed. This includes agility, information, restructuring and } \\
\text { experimentation. }\end{array}$ \\
\hline
\end{tabular}


Table 1 (cont.). Research articles integrated into the corporate agility model

\begin{tabular}{|c|c|c|}
\hline Author & Title & Concepts integrated \\
\hline $\begin{array}{l}\text { Cegarra-Navarro, Juan- } \\
\text { Gabriel; Soto-Acosta, Pedro; } \\
\text { Wensley, Anthony K.P. }\end{array}$ & $\begin{array}{l}\text { ructured knowledge processes } \\
\text { d firm performance: The role of } \\
\text { ganizational agility }\end{array}$ & $\begin{array}{l}\text { Organizational agility mediating the relationship between knowledge } \\
\text { application and form performance. Precondition is a conversion process of the } \\
\text { acquired knowledge. }\end{array}$ \\
\hline $\begin{array}{l}\text { Cegarra-Navarro, Juan- } \\
\text { Gabriel; Martelo-Landroguez, } \\
\text { Silvia }\end{array}$ & $\begin{array}{l}\text { The effect of organizational } \\
\text { memory on organizational agility }\end{array}$ & $\begin{array}{l}\text { Transferring and retrieving knowledge to stimulate the creation of intellectual } \\
\text { capital and analyze the constantly changing environment to adapt and change } \\
\text { if necessary. }\end{array}$ \\
\hline $\begin{array}{l}\text { Cepeda, Juan; Arias-Pérez, } \\
\text { José }\end{array}$ & $\begin{array}{lrr}\text { Information } & \text { technology } \\
\text { capabilities } & \text { and } & \text { organizational } \\
\text { agility } & & \\
\end{array}$ & $\begin{array}{l}\text { Requirements for IT and data processing capabilities that support the } \\
\text { exploitation of open innovation. Created data and knowledge needs to be } \\
\text { shared with partners. }\end{array}$ \\
\hline Denning, Stephen & $\begin{array}{l}\text { gile: it's time to put it to use to } \\
\text { anage business complexity }\end{array}$ & \\
\hline Denning, Stephen & $\begin{array}{l}\text { How to make the whole } \\
\text { organization "Agile" }\end{array}$ & $\begin{array}{l}\text { Changing leadership to an "agile mindset" } 1 \\
\text { mindset that includes a top-down bureaucr } \\
\text { management, customers, and workers. }\end{array}$ \\
\hline $\begin{array}{l}\text { Eshlaghy, Abbas } \text { Toloie; } \\
\text { Mashayekhi, Ali N.; } \\
\text { Rajabzadeh, Ali; Razavian, } \\
\text { Mir Majid }\end{array}$ & $\begin{array}{l}\text { Applying path analysis method in } \\
\text { defining effective factors in } \\
\text { organizational agility }\end{array}$ & $\begin{array}{l}\text { Required set of enablers for an organization that ensure agile capabilities like } \\
\text { flexibility, responsibility, competency, and speed. In addition, agile drivers } \\
\text { describing the VUCA from a different viewpoint. }\end{array}$ \\
\hline $\begin{array}{l}\text { Felipe, Carmen M.; Roldán, } \\
\text { José L.; Leal-Rodríguez, } \\
\text { Antonio L. }\end{array}$ & $\begin{array}{l}\text { In explanatory and predictive } \\
\text { hodel for organizational agility }\end{array}$ & $\begin{array}{l}\text { Information system capabilities impact the absorptive capacity of an } \\
\text { organization and directly organizational agility. Hierarchical culture can } \\
\text { prevent though the absorptive capacity to be transmitted to organizational } \\
\text { agility. }\end{array}$ \\
\hline $\begin{array}{l}\text { Ganguly, Anirban; Nilchiani, } \\
\text { Roshanak; Farr, John V. }\end{array}$ & $\begin{array}{l}\text { Evaluating agility in corporate } \\
\text { enterprises }\end{array}$ & $\begin{array}{l}\text { gility drivers describing the business environment that explain the need for } \\
\text { sessing agility. These include e.g. price sensitivity, changed customer } \\
\text { eferences and technological changes. }\end{array}$ \\
\hline $\begin{array}{l}\text { King, Elizabeth; Badham, } \\
\text { Richard }\end{array}$ & eadership in uncertainty & \\
\hline Nijssen, M.; Paauwe, J. & $\begin{array}{l}\text { RM in turbulent times: how to } \\
\text { hieve organizational agility? }\end{array}$ & ighly \\
\hline $\begin{array}{l}\text { Nurdiani, Indira; Börstler, } \\
\text { Jürgen; } \quad \text { Fricker, Samuel; } \\
\text { Petersen, Kai; Chatzipetrou, } \\
\text { Panagiota }\end{array}$ & $\begin{array}{l}\text { tanding the order of agile } \\
\text { introduction: Comparing } \\
\text { maturity models and } \\
\text { oners' experience }\end{array}$ & $\begin{array}{l}\text { Concepts to transfer agile methods onto organizational level and practical } \\
\text { implications. E.g. minimization of ambiguity through user stories while } \\
\text { iterative reviews ensure integration of customer preferences. }\end{array}$ \\
\hline Ravichandran, T. & $\begin{array}{l}\text { Exploring the relationships } \\
\text { between IT competence, } \\
\text { innovation capacity and } \\
\text { organizational agility }\end{array}$ & $\begin{array}{l}\text { IT competence including information system capabilities and investment } \\
\text { orientation impact through digital platform capabilities organizational agility. } \\
\text { Innovation capacity mediates this correlation. }\end{array}$ \\
\hline $\begin{array}{l}\text { Rigby, Darrell } \quad \text { K., Jeff } \\
\text { Sutherland, and Hirotaka } \\
\text { Takeuchi }\end{array}$ & $\begin{array}{l}\text { ng Agile - How to Master } \\
\text { ess That's Transforming } \\
\text { nent }\end{array}$ & ket \\
\hline $\begin{array}{l}\text { Shams, Riad; Vrontis, } \\
\text { Demetris; Belyaeva, Zhanna; } \\
\text { Ferraris, Alberto; Czinkota, } \\
\text { Michael R. }\end{array}$ & $\begin{array}{l}\text { Strategic agility in international } \\
\text { business: A conceptual framework } \\
\text { for "agile" multinationals }\end{array}$ & $\begin{array}{l}\text { Drivers and triggers of strategic agility. Specifying strategic agility through } \\
\text { supply chain agility, IT agility and agile and sustainable productions. }\end{array}$ \\
\hline $\begin{array}{lr}\text { Sherehiy, } & \text { Bohdana; } \\
\text { Karwowski, } & \text { Waldemar; } \\
\text { Layer, John K. } & \\
\end{array}$ & $\begin{array}{l}\text { A review of enterprise agility: } \\
\text { Concepts, frameworks, } \begin{array}{r}\text { and } \\
\text { attributes }\end{array}\end{array}$ & $\begin{array}{l}\text { Comprehensive set of characteristics of agile enterprises focused on the } \\
\text { organization and workforce. Integration of approaches towards authority, } \\
\text { proactivity and HRM practices. }\end{array}$ \\
\hline $\begin{array}{ll}\text { David Wiraeus; James } \\
\text { Creelman }\end{array}$ & $\begin{array}{l}\text { How to Build an Agile and } \\
\text { Adaptive Balanced Scorecard }\end{array}$ & $\begin{array}{l}\text { Process to build an agile and adaptive balanced scorecard system which } \\
\text { includes cross-enterprise collaboration and disruptive innovation management. }\end{array}$ \\
\hline Wageeh, Nafei A. & $\begin{array}{l}\text { Organizational Agility: The Key to } \\
\text { Organizational Success }\end{array}$ & $\begin{array}{l}\text { Impacts of sensing agility, decision making agility and acting agility on } \\
\text { organizational success. }\end{array}$ \\
\hline $\begin{array}{l}\text { Xing, Yijun; Liu, Yipeng; } \\
\text { Boojihawon, Dev K.; Tarba, } \\
\text { Shlomo }\end{array}$ & $\begin{array}{l}\mathrm{m} \text { and strategic } \\
\text { tual framework } \\
\text { a }\end{array}$ & $\begin{array}{l}\text { Conceptual framework that highlights leadership unity, resource fluidity and } \\
\text { strategic sensitivity as parts of strategic agility. }\end{array}$ \\
\hline $\begin{array}{l}\text { Zitkiene, Rima; Deksnys, } \\
\text { Mindaugas }\end{array}$ & $\begin{array}{l}\text { Organizational Agility Conceptual } \\
\text { Model }\end{array}$ & ies, \\
\hline
\end{tabular}

Source: Compiled by the authors.

These 23 frameworks give a comprehensive overview which elements are essential when implementing organizational agility. During this research the frameworks, models and theories were reviewed, and elements were aligned in dependence on their response to volatility, uncertainty, complexity, and ambiguity. In this course the four VUCA terms were defined to develop a common understanding on what characterizes each of the four 
acronym parts and how they are separate from each other. The target of this research is to provide a practical model that compresses all parts of organizational agility into a fast and easy understandable model.

\section{Results}

Each part of VUCA is a different challenge and requires a different type of response from the agile framework. Bennett and Lemoine (2014) showed in their iteration of organization performance that by ignoring important disparities between volatility, uncertainty, complexity, and ambiguity leaders are left disempowered. To better distribute organizational resources aiming at maintaining and boosting corporate efficiency, it needs to be explained how managers can understand the distinctions between these dynamic environmental circumstances.

\section{Volatility}

A volatile environment can be referred to as being an unstable and unpredictable change. It is certain that change constantly happens but there is no information about the point of time, magnitude, and direction the environment is adjusting. Examples can be a change in the intensity of competition, customer requirements or drastic social changes (Eshlaghy et al., 2010). That way organizations need to take precautions to be capable to react to these unavoidable changes with a different set of resource fluidity (Xing et al., 2020). One enabler are slack resources or at least a plan how resources or capacities can quickly be aligned to the new situation through a fast scalable workforce (Bennett and Lemoine, 2014; Nijssen and Paauwe, 2012; Appelbaum et al., 2017b; Baškarada and Koronios, 2018). Latter certainly is less cost intensive than constantly carrying a surplus of resources. That way agility is kept during volatile changes in the economic surrounding. The organizational structure needs to be aligned to answer flexible and fast to those inevitable changes. On one hand this refers to fluid role definition to be exchanged against static job descriptions (Sherehiy et al., 2007). On the other hand a hierarchical top-down structure is unlikely to have fast decision work flows which asks for a setting in which decision power is distributed and employees on lower hierarchical levels are empowered (Eshlaghy et al., 2010). Thus, volatility requires flat hierarchies combined with minimal formal authority (Nijssen and Paauwe, 2012). Instead of authority and decision making power being attributed to certain managers it should be tied to tasks which results in a scenario where the person identifying a need for action can directly counteract against such development ensuring organizational performance (Sherehiy et al., 2007). Such flexibility does also include a scalable workforce and production systems. Summarizing, volatility requires a certain set of enablers namely slack resources, agility and decentralized power (Eshlaghy et al., 2010; Sherehiy et al., 2007; Zitkiene and Deksnys, 2018). These enablers need to be inherent within the organization and its structure. Discerning is the long time it takes to install these enablers while volatility requires with fast actions exactly the opposite.

\section{Uncertainty}

Lack of knowledge on what and how significant changes will happen describes the term uncertainty. It has a different meaning than volatility as the unknow does not lie in the magnitude or timing of a shift but rather if any change will happen (Bennett and Lemoine, 2014). Tackling uncertainty has the main objective to gather as much real time information and knowledge as possible by sensing all parts of the environment for external changes (Zitkiene and Deksnys, 2018). This knowledge has to be compressed so that it can be quickly taken into consideration (Cegarra-Navarro and Martelo-Landroguez, 2020) which requires information technology and data processing capabilities (Cepeda and Arias-Pérez, 2019; Felipe et al., 2016; Ravichandran, 2018). As uncertainty can have it cause in various angles all those parts of the environment have to be taken into consideration. This can be governmental decisions, competitors, or customer strategies as well as financial or environmental impacts which an organization must constantly monitor to be able to assess future developments. Termed as organizational mindfulness it includes awareness, attention and acceptances (King and Badham, 2019). Making future preference or requirements of the companies customers more certain necessitates strong connection and cooperation with customers (Baran and Woznyj, 2020; Rigby et al., 2016). In the Scrum methodology this is ensured be the product owner who puts the requirements for software engineering through a kind of lens (Nurdiani et al., 2019). For a full organizational inclusion of agile linkages also suppliers should be aligned as strong agile partners (Appelbaum et al., 2017b). As uncertainty can derive from any direction and masses of data can be collected it needs absorptive data processing capacities to process the information which describes another 
important sensing tool. Hierarchical cultures can prevent though that knowledge and information is transferred to where it is required (Felipe et al., 2016; Cegarra-Navarro et al., 2016) which makes the link to flat hierarchies as an enabler to respond to volatility. Namely the knowledge produced internally should be shared with partners and all employees which reinforces the customer focus (Cepeda and Arias-Pérez, 2019). To decrease uncertainty to the lowest possible degree not only the organization needs to turn agile but ideally a fully agile supply-chain is implemented to achieve strategic agility (Shams et al., 2020). Summarizing the organization needs to integrate sensing tools to make the uncertain environment more certain and that way more manageable (Baškarada and Koronios, 2018). The sensing mechanisms include IT and data systems, knowledge and data gathering and a strong customer focus as proposed by Scrum.

\section{Complexity}

Interconnected parts characterize a complex world. One successful the way an organization can address complexity is by implementing a structure that mirrors the environment (Bennett and Lemoine, 2014). Strangely though the organization should try to simplify workflows, processes and IT systems to prevent adding proprietary complexity to the environmental complex systems and interlinkages (Sherehiy et al., 2007). Practically this means that market or customer structure should be reflected in the organizations departments or even better agile team structures that constantly adapt to the changing outside systems through cross-enterprise collaboration (Baškarada and Koronios, 2018; Wageeh, 2016; Wiraeus and Creelman, 2019). In the same step processes and workflows should always be examined with the purpose to reduce their complexity. As complex materials or situations are hard to plan or forecast the outcome, an iterative working practice helps to do small steps into the right direction (Baran and Woznyj, 2020; King and Badham, 2019; Nurdiani et al., 2019). This process reflects an organizational learning approach (Appelbaum et al., 2017b). The knowledge creation and alignment process described as a response to uncertainty must be structured to support organizational learning. Knowledge creation includes the sharing of knowledge across departments and team but also by experimentation and simulation (Nijssen and Paauwe, 2012; Baran and Woznyj, 2020; Cegarra-Navarro and Martelo-Landroguez, 2020; Cegarra-Navarro et al., 2016). Supported is this learning curve by cross-functional teamwork to ensure that the highest knowledge capacity possible tackles the complex issue (Eshlaghy et al., 2010). Mistakes within the iterative working attitude need to be seen as valuable learning (Rigby et al., 2016). Summarizing the combination of an iterative approach, cross-functional teamwork and fostered organizational learning ensure dealing with complex environments. While iterative learning and working methods can be quickly implemented, the restructuring of the organization towards these practices needs long term commitment and a cultural shift towards error handling methods rather than error prevention.

\section{Ambiguity}

In ambiguous situations it is hard to identify the cause-and-effect relationships. Ambiguous situations usually represent new products, market structures or technologies. Due to the new nature a responding with gathering information or having slack resources does not prepare an organization to cope with ambiguous issues. Instead ambiguity requires acting agility to external change which converts the situation of the organization (Wageeh, 2016; Zitkiene and Deksnys, 2018). Alternatively an experimentative mindset is required as for example it is not clear how customers will react to a new product or technology (Bennett and Lemoine, 2014). That way it is closely linked to customer partnerships and iterative work approach with constant discussions and reflecting like in the Scrum methodology (Nijssen and Paauwe, 2012). This way clear user stories or in other words customer requirements and preferences minimize ambiguity (Nurdiani et al., 2019). The development of a product through to the end based on believed customer preferences is not intended anymore but rather an experimental attitude with several options which leave the final solution open and enable customer response integration. The innovation capacity is a crucial point to answer ambiguity because multiple approaches and new ways of thinking are required (Ravichandran, 2018). Bing self-innovative and creative is another response to ambiguity which can be reinforced by radical agile management and reduction of hierarchical bureaucracy (Denning, 2015) making the link to agile enablers. Disruptive innovation changes the organization from a reactive position into a proactive one (Wageeh, 2016; Wiraeus and Creelman, 2019). For the exploitation capability of open innovation organizations can trigger technological leaps instead of reacting to them (Cepeda and Arias-Pérez, 2019). This requires proactivity by 
leaders and employees. Proactivity in a context involves anticipation of problems caused by ambiguity and initiative to find solutions for change related problems (Sherehiy et al., 2007). Summarizing ambiguity implicates innovation, proactivity, and experimentation as agile responses.

To condense the results deviated above a model was created that brings the environmental forces volatility, uncertainty, complexity, and ambiguity into context with agile characteristics an organization should incorporate as a response.

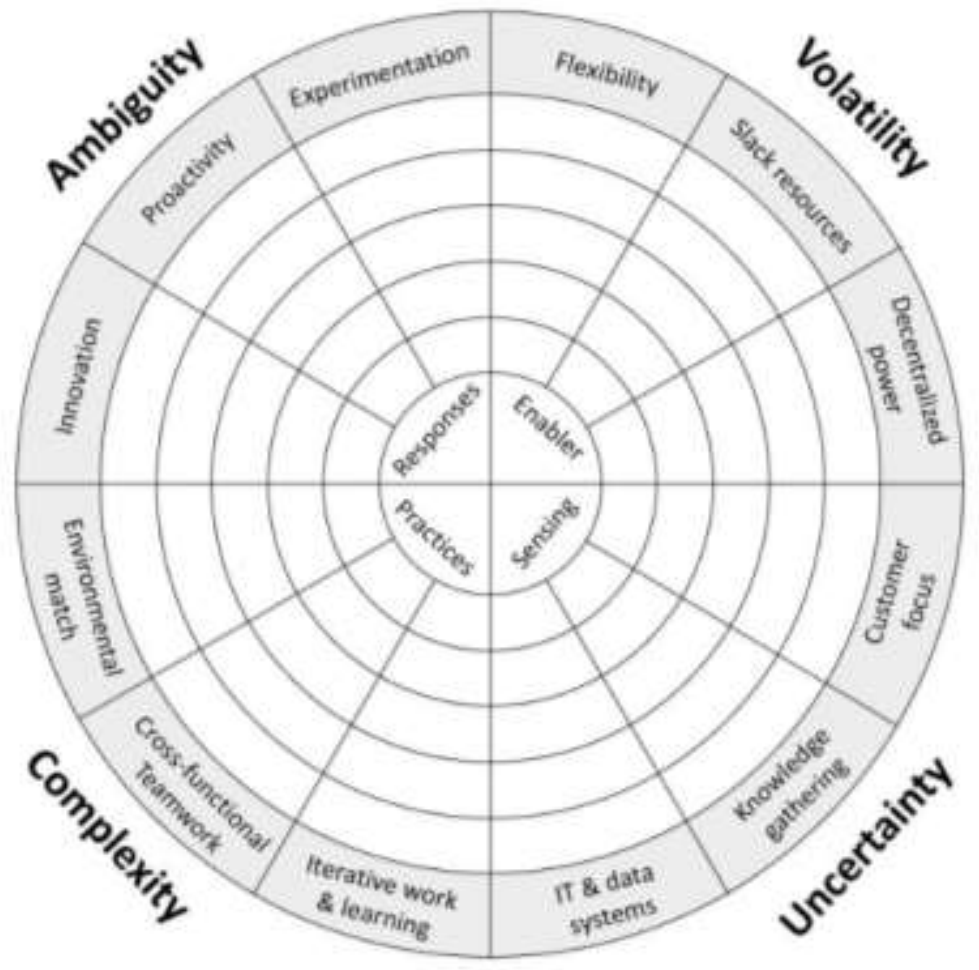

Figure 1. Agile characteristics to deal with VUCA forces

Source: compiled by the authors.

The model highlights that for dealing with volatility an organization should incorporate certain enablers. The existence of volatility is certain whilst only the timing, magnitude and direction cannot be foreseen. Therefore, it is still worthwhile to invest into these enablers as slack resources might seem like waste in a fist place but can secure profitability and competitive advantage of the organization in especially volatile circumstances like the COVID-19 pandemic. While some industries were confronted with a drastic decrease in business and income like the aviation industry or hospitality sector, other were confronted with a massive increase. Especially online traders, DIY stores or pet product retailers can be named. The ones having slack resources in their organization were able to react faster to the increased business opportunities. Flexibility for example in the work force or logistical capabilities allows to adapt to volatile situation in both directions. Decentralized power on the other hand enables quick reaction and detection of volatility and makes that way the transition to the organizational sensing characteristics to deal with uncertainty. The stronger the connection or even partnership with customers is, the more knowledge or even data can be obtained to get some certainty into such an economic scenario.

Complexity on the other hand makes it impossible to foresee and plan the future reliably. Practices like iterative work, learning methods and cross-functional teamwork are procedures that allow to make progress without knowing the exact final requirement or outcome. On an organizational level the structure is required to match the environment. This can refer to the customer structure, governmental policies, or the supplier composition. The better these outside factors are matched internally the better an organization copes with complexity. In addition, this practice supports customer focus and knowledge gathering due to close and represented connection with the 
environment. Finally, ambiguity requires a set of responses. Innovation focus aims at being disruptive on its own instead of having to react to ambiguous customer needs or technological leaps by competitors which leave it unclear how the organization should respond. Proactivity and experimentation support this progress and are in close association with iterative work and learning practices that are required to deal with complexity.

\section{Discussion}

Surprisingly, the created model does not include two important pillar of business research and practice, namely strategy and leadership. This consequently brings up the question if these two elements or even managers entirely get obsolete in a VUCA environment or how an organization should handle these two important elements in management.

\section{What about strategy?}

Agile strategy means nothing more than the strategic commitment to implement agile working methods into the organization. Strategic in certain ways is contradictive to agile responses but with regards to brand key, operating markets, and sectors it remains as an inevitable element of management and leadership. The only thing that needs to be added as a continuum is commitment to agile methods summarized in this article (Appelbaum et al., 2017a). Strategic agility furthermore includes supply chain agility and IT agility (against uncertainty) as well as agile and sustainable productions to cope with volatility (Shams et al., 2020). Thus, strategy committing towards agile practices and structures is rather seen as a prerequisite than a single element of the agile model. If this direction is not supported and the importance for dealing with VUCA is not seen, the described enablers, practices and responses will never find its way to be a substantial part of the corporate culture. Consequently, leadership must support this direction in the first place.

\section{What about leadership?}

Leadership is not a specific element in the model to assess agility. How can this be? The same as strategy it is a precondition, and the main condition is that leadership has an "agile mindset". This means to replace the hierarchical mindset that includes a top-down bureaucracy with a constant interaction of management, customers, and workers (Denning, 2016). To deal with uncertainty and ambiguity mindfulness in leadership ensures inclusive and pragmatic work attitudes which reinforces the identification of employees (King and Badham, 2019). Transforming an organization agile requires large changes from managers. That way leadership unity towards the common goal is especially important to balance efficiency and flexibility in dynamic environments (Xing et al., 2020). Consequently, ambidexterity in leadership will enable the organization to be experimental, innovative and even have slack resources by ensuring the profitability through exploitation of well-placed products and services (Du and Chen, 2018). Agile working practices include handing responsibility and authority to employees. One question remains mostly open in agile transformations of organization. Who is in charge for disciplinary guidance of workers? Organizations have found a wide range of answers to the question, ranging from being part of the Scrum Masters role to specialized people manager who lead between 20 to 40 employees. In conclusion organizations must subordinate the topic of leadership the same model as described in this paper. Use experimentation and iterative work processes to make the development of the leadership role a continuous learning process. Thus, leadership is not an element of the agile transformation model but rather an internal factor that can be developed through application of the sensing, responding and practice elements of the model internally.

\section{Conclusion}

From the literature review a comprehensive model for developing corporate agility was created. It brings elements of corporate agility into direct context to volatility, uncertainty, complexity, and ambiguity as these environmental forces have proven to main economic scenarios in the pandemic year 2020. Practical applicability and acceptance are provided through the adaption of a similar visualization as the corporate culture model by Denison (Denison et al., 2004). It is a common assessment tool with worldwide practitioners. By underlying the 12 elements additionally leadership and strategy can be developed. It must be highlighted though that a basic requirement for application is a strategic commitment to organizational agility as a prerequisite. Scientific and practical relevance of the developed model is provided through the dramatic governmental, economic, and social changes 
organizations have experienced as a consequence of COVID-19. Outside the scope of this research were the development of scales for each element. As further research on the created model we suggest the creation of a model-based questionnaire to allow practitioners the assessment of the agile status quo of their organization. Possibly it can be related to gather sectoral scientific evidence on how advance in terms of agile practices enterprises are as this would make results comparable.

Funding: self-funded.

Author contribution: conceptualization, Henning Bundtzen; data curation, Henning Bundtzen; formal analysis, Henning Bundtzen and Gerriet Hinrichs; funding acquisition, Henning Bundtzen and Gerriet Hinrichs; investigation, Gerriet Hinrichs and Henning Bundtzen; methodology, Henning Bundtzen and Gerriet Hinrichs; project administration, Henning Bundtzen and Gerriet Hinrichs; resources, Henning Bundtzen and Gerriet Hinrichs; software, Henning Bundtzen and Gerriet Hinrichs; supervision, Henning Bundtzen and Gerriet Hinrichs; validation, Henning Bundtzen and Gerriet Hinrichs; visualization, Henning Bundtzen; writing - original draft, Henning Bundtzen and Gerriet Hinrichs; writing - review \& editing, Henning Bundtzen and Gerriet Hinrichs.

\section{References}

1. Appelbaum, Steven H.; Calla, Rafael; Desautels, Dany; Hasan, Lisa (2017a). The challenges of organizational agility (part 1). Ind and Commercial Training, 49 (1), 6-14. DOI: 10.1108/ICT-05-2016-0027.

2. Appelbaum, Steven H.; Calla, Rafael; Desautels, Dany; Hasan, Lisa N. (2017b). The challenges of organizational agility: part 2. Ind and Commercial Training, 49 (2), 69-74. DOI: 10.1108/ICT-05-2016-0028.

3. Baran, Benjamin E.; Woznyj, Haley M. (2020). Managing VUCA: The human dynamics of agility. Organizational Dynamics, S. 100787. DOI: 10.1016/j.orgdyn.2020.100787.

4. Baškarada, Saša; Koronios, Andy (2018). The 5S organizational agility framework: a dynamic capabilities perspective. IJOA, 26 (2), 331-342. DOI: 10.1108/IJOA-05-2017-1163.

5. Bennett, Nathan; Lemoine, G. James (2014). What a difference a word makes: Understanding threats to performance in a VUCA world. Business Horizons, 57 (3), 311-317. DOI: 10.1016/j.bushor.2014.01.001.

6. Cegarra-Navarro, Juan-Gabriel; Martelo-Landroguez, Silvia (2020). The effect of organizational memory on organizational agility. JIC, 21 (3), S. 459-479. DOI: 10.1108/JIC-03-2019-0048.

7. Cegarra-Navarro, Juan-Gabriel; Soto-Acosta, Pedro; Wensley, Anthony K.P. (2016). Structured knowledge processes and firm performance: The role of organizational agility. Journal of Business Research, 69 (5), 1544-1549. DOI: 10.1016/j.jbusres.2015.10.014.

8. Cepeda, Juan; Arias-Pérez, José (2019). Information technology capabilities and organizational agility. MBR, 27 (2), 198-216. DOI: 10.1108/MBR-11-2017-0088.

9. David Wiraeus; James Creelman (2019). How to Build an Agile and Adaptive Balanced Scorecard. Agile Strategy Management in the Digital Age: Palgrave Macmillan, Cham, 89-112. Available at: https://link.springer.com/chapter/10.1007/978-3-319-76309-5_5.

10. Denison, Daniel R. (1984): Bringing corporate culture to the bottom line. Organizational Dynamics, 13 (2), 5-22. DOI: 10.1016/0090-2616(84)90015-9.

11. Denison, Daniel R.; Haaland, Stephanie; Goelzer, Paulo (2004). Corporate Culture and Organizational Effectiveness. Organizational Dynamics, 33 (1), 98-109. DOI: 10.1016/j.orgdyn.2003.11.008.

12. Denning, Stephen (2015). Agile: it's time to put it to use to manage business complexity. Strategy \& Leadership, 43 (5), 10-17. DOI: 10.1108/SL-07-2015-0057.

13. Denning, Stephen (2016). How to make the whole organization "Agile". Strategy \& Leadership, 44 (4), 10 17. DOI: $10.1108 / \mathrm{SL}-06-2016-0043$.

14. Du, Jingjing; Chen, Zhongwei (2018). Applying Organizational Ambidexterity in strategic management under a "VUCA" environment: Evidence from high tech companies in China. International Journal of Innovation Studies, 2 (1), 42-52. DOI: 10.1016/j.ijis.2018.03.003. 
15. Eshlaghy, Abbas Toloie; Mashayekhi, Ali N.; Rajabzadeh, Ali; Razavian, Mir Majid (2010). Applying path analysis method in defining effective factors in organisation agility. International Journal of Production Research, 48 (6), 1765-1786. DOI: 10.1080/00207540802566410.

16. Felipe, Carmen M.; Roldán, José L.; Leal-Rodríguez, Antonio L. (2016). An explanatory and predictive model for organizational agility. Journal of Business Research, 69 (10), 4624-4631. DOI: 10.1016/j.jbusres.2016.04.014.

17. Ganguly, Anirban; Nilchiani, Roshanak; Farr, John V. (2009). Evaluating agility in corporate enterprises. In: International Journal of Production Economics, 118 (2), 410-423. DOI: 10.1016/j.ijpe.2008.12.009.

18. King, Elizabeth; Badham, Richard (2019): Leadership in uncertainty. Organizational Dynamics, 48 (4), 100674. DOI: $10.1016 /$ j.orgdyn.2018.08.005.

19. Nijssen, M.; Paauwe, J. (2012). HRM in turbulent times: how to achieve organizational agility? In: The International Journal of Human Resource Management, 23 (16), 3315-3335. DOI: 10.1080/09585192.2012.689160.

20. Nurdiani, Indira; Börstler, Jürgen; Fricker, Samuel; Petersen, Kai; Chatzipetrou, Panagiota (2019): Understanding the order of agile practice introduction: Comparing agile maturity models and practitioners' experience. Journal of Systems and Software, 156, 1-20. DOI: 10.1016/j.jss.2019.05.035.

21. Ravichandran, T. (2018). Exploring the relationships between IT competence, innovation capacity and organizational agility. The Journal of Strategic Information Systems, 27 (1), 22-42. DOI: 10.1016/j.jsis.2017.07.002.

22. Rigby, Darrell K., Jeff Sutherland, and Hirotaka Takeuchi (2016): Embracing Agile. How to Master the Process That's Transforming Management. Harvard business review, 94 (5), 40-50. Available at: https://hbr.org/2016/05/embracing-agile.

23. Shams, Riad; Vrontis, Demetris; Belyaeva, Zhanna; Ferraris, Alberto; Czinkota, Michael R. (2020). Strategic agility in international business: A conceptual framework for "agile" multinationals. Journal of International Management, p. 100737. DOI: 10.1016/j.intman.2020.100737.

24. Sherehiy, Bohdana; Karwowski, Waldemar; Layer, John K. (2007): A review of enterprise agility: Concepts, frameworks, and attributes. International Journal of Industrial Ergonomics, 37 (5), 445-460. DOI: 10.1016/j.ergon.2007.01.007.

25. Wageeh, Nafei A. (2016). Organizational Agility: The Key to Organizational Success. IJBM, 11 (5), p. 296. DOI: $10.5539 /$ ijbm.v11n5p296.

26. Xing, Yijun; Liu, Yipeng; Boojihawon, Dev K.; Tarba, Shlomo (2020). Entrepreneurial team and strategic agility: A conceptual framework and research agenda. Human Resource Management Review, 30 (1), p. 100696. DOI: $10.1016 /$ j.hrmr.2019.100696.

27. Zitkiene, Rima; Deksnys, Mindaugas (2018): Organizational Agility Conceptual Model. Montenegrin Journal of Economics, 14 (2), p. 115-129. DOI: 10.14254/1800-5845/2018.14-2.7. 